that China and the United States should enhance peopleto-people exchanges to build stronger ties where the two countries have the least disagreements and the most consensus. Sino-US competition on the annual university international rankings may become more intense as PRC universities strive to attain world-class status, but that pales in comparison to what strong bilateral university relations means for addressing global problems and maintaining geopolitical stability. Before Trump, China-US ties clearly were more resilient and dynamic. The two countries could carry out strategic and forward-looking dialogues around critical issues for mutual benefit. At present, universities in both countries may not be able to eliminate the trade distortions and confrontations that currently occupy the attention of the Trump and XI Jinping administrations, but there is much they can do to keep US-China relations on an even keel as the relationship reconfigures itself to better reflect current political and economic realities. Students from both countries eventually will become future leaders in government, business, and academia; hopefully, greater mutual understanding developed through cooperative learning and cross-cultural exchange will help to soften some of the current mistrust and pave the way for more reasoned and balanced conversations in the years ahead.

DOI: http://dx.doi.org/ro.6oI7/ihe.2019.96.10796

\section{Not Your Parents' Internationalization: Next Generation Perspectives}

\section{Laura E. Rumbley and Douglas Proctor}

Laura E. Rumbley is associate director at the Center for International Higher Education, Boston College, US. E-mail: rumbley@bc.edu. Douglas Proctor is director of International Affairs at University College Dublin, Ireland.E-mail: douglas.proctor@ucd.ie.

Tnternationalization of higher education is generally con1 sidered to be a "young" phenomenon-as a field of inquiry, an area of professional practice, and a strategic undertaking for higher education institutions. Even so, there is today a sizable corpus of published material on the subject, and a recognized cadre of experts whose work has shaped the field in profound and long-lasting ways. The contemporary "founders" of the study of internationalization stand out for the contributions they have made in proposing and defining key terms, positing conceptual frameworks, shap- ing relevant debates, drawing the attention of a multitude of stakeholders, and connecting theory with policy and practice.

The intellectual evolution of internationalization has occurred in tandem with the development, around the world, of a community of organizations dedicated to serving international education through programming, knowledge development, and/or professional training for those working in this field. Some of these organizations are decades old, including the Institute of International Education in the United States, which celebrates Ioo years in 20I9; the German Academic Exchange Service (DAAD), founded in I925; NAFSA: Association of International Educators, which was established in the United States in I948; and The Netherlands-based European Association for International Education, which dates from i989. These entities - and the plethora of related organizations and associations that operate at national, (sub)regional, and (inter) continental levels around the world-have set the scene for much of the conversation and the action agenda connecting international education globally. Indeed, the founding scholars and organizations in international education have had an immensely influential role in determining how we understand and enact internationalization in higher education worldwide.

Acknowledging both the utility and the "baggage" that the past provides, important questions arise as we simultaneously reflect on where we have come from and where we are headed, as we hurtle toward the end of the second decade of the twenty-first century: How and in what ways can "next generation" perspectives on internationalization of higher education lead us meaningfully into the future? Why does innovation-both in terms of sources of information and content-matter? From our perspective, the increasing complexity of the global higher education landscape, the rapid evolution of internationalization dynamics, and the high stakes connected to quality in higher education and human capital development in a global context, make it crucial to (re)focus the conversation on internationalization across new modes, new contexts, and new topics. Considering these matters through a collection of new voices from around the world is also vital, if we are serious about understanding and responding to the possibilities and challenges that lie ahead.

\section{New Modes, New Topics, New Contexts}

Previous exploration into various data sources has given us a clear indication that research on higher education is overwhelmingly concentrated in a relatively small number of research centers located in a select number of (wealthy, largely English-speaking) countries. Furthermore, research output specifically on internationalization in higher educa- 
tion is similarly clustered, emanating disproportionately from Australia, Europe, and North America. Certain topics are also overrepresented in the literature at our fingertips, ranging from the American study abroad experience to the international student adaptation process and to the single program or institutional case study analysis. Quite literally, a world of dimensions related to the phenomenon of internationalization remains poorly researched or ignored altogether.

To rectify this situation, commitments to explore new modes, new topics, and new contexts for internationalization must be made by key stakeholders. These stakeholders include governments and policy organizations that frame lines of inquiry to explore and fund for research; established researchers with the ability to determine their individual agendas for ongoing scholarship, and to influence peers within their networks; as well as graduate students and young academics undertaking preliminary theses, dissertations, and early post-doc projects, and the advisors guiding these early career individuals.

\section{Given the complex and dynamic world in which we are living, new topics for internationalization should be finding their way into our collective knowledge base every day.}

\footnotetext{
New Contexts: The "Where”

Internationalization is clearly a worldwide phenomenon, yet the bulk of research is still produced by-and concerned with-large English-speaking countries in the global North. As such, new contexts for internationalization include countries and regions of the world, categories of institutions, and other settings where there has been limited research to date. Examples we are familiar with of research being undertaken in relation to new contexts include a focus on remote geographic locations and/or highly marginalized communities (e.g., due to the predominance of a non-widely spoken language, or the prevalence of insecurity or cultural isolation), or in contexts of extreme economic crisis or deprivation. What do we really know about internationalization of higher education in contested borderlands, in relation to indigenization movements, in regions with highly inhospitable climates, or in remote rural or wilderness settings? We know of several young researchers who
}

are digging into these topics, and more need to be encouraged.

\section{NeW TOPICS: ThE "WhAT"}

Given the complex and dynamic world in which we are living, new topics for internationalization should be finding their way into our collective knowledge base every day. We note with excitement a number of early career researchers who are looking at how internationalization of higher education serves the surging numbers of individuals coping with forced migration around the world. Others are helping us learn from internationalization efforts undertaken at primary and secondary education institutions in different contexts and to reflect on how internationalization intersects with the formation of individual identity, national identity, and regional engagement in various regions of the world. Still others are exploring ways in which we may leverage internationalization in the approach to training future academics, or advancing the work of university-based schools and faculties of education, among other themes. The need for attention to new topics in relation to internationalization is acute, and broader exploration of the landscape around us requires sustained attention and support.

\section{New Contexts: The "How"}

New methods for researching internationalization push us collectively toward important considerations about how our knowledge base is developed in this field. The work of a number of early career researchers we are familiar with is giving us insight into everything from the possibilities of mining existing data sets for deeper understanding about the choices of internationally mobile students and the dynamics of their satisfaction; to the potential for topic modeling to make sense of a wide-ranging pool of government policies and initiatives focused on internationalization in different national contexts; and the philosophical and historical considerations of Protestant roots undergirding the Western theory of internationalization. From biological processes to narrative analysis, the methodologies for exploring the phenomenon of internationalization can be taken in a range of compelling directions that should offer consequential insights over time.

\section{May the Force Be with the Next Generation}

An uncertain future for internationalization offers both opportunities and challenges for the next generation of scholars and scholar-practitioners who are committed to ensuring that international engagement and global learning play their rightful role in advancing both high quality and equitable education, knowledge development, and social relevance in the coming decades. The work of the rising 
generation of internationalization specialists has significant potential to achieve these ends, building creatively and dynamically on all that has come before.

DOI: http://dx.doi.org/Io.6oI7/ihe.20I9.96.10772

\section{International Student Mobility in Israel}

\section{AN NetTe BAM BERGER}

Annette Bamberger is a PhD candidate at the Institute of Education, University College London, UK. E-mail: a.bamberger.14@ucl.ac.uk.

$\mathrm{W}_{\mathrm{p} \text { timata }}$ ith respect to research, Israeli universities have impressive international funding and publication and citation rankings; however, with respect to receiving international students, Israel performs poorly compared to the OECD average of 9 percent, with only I.4 percent of its student population coming from abroad. This has caused concern and attracted the attention of the Council for Higher Education (CHE) - Israel's central body charged with coordinating the higher education (HE) system-and of its funding arm, the Planning and Budgeting Committee (PBC). In a new multi-year plan announced in July 2017 , internationalization was identified as a key focus, with the goal of doubling the number of international students to 25,000 within five years.

\section{Historical Development and Contem porary Issues}

While the first students at Israeli universities in the preState era were predominantly from Eastern Europe, since the early decades of the State, most students in Israeli universities have been local. Due to the intractable Israeli-Palestinian conflict, regional student mobility to Israel is nearly nonexistent. Yet, international students have not been ignored. Starting in I955, international student programs targeting American Jewish students on a junior year/semester abroad were developed as a result of the coordination between universities, the government, and diaspora community organizations. In addition to the academic component (emphasizing the Hebrew language, Jewish studies, Israel studies, and Middle Eastern studies), cultural and social activities, tours throughout the country, and encounters with local Israelis also formed an integral part of the programs. Since the language of instruction in these programs was predominately English and students required specialized support (for visa, housing, etc.), separate infrastructures gradually developed to service these programs and students. While the programs were open to all, and international students from a variety of backgrounds welcomed, the programs were primarily targeted at a Jewish population, as demonstrated by marketing and recruitment; funding; support services; and formal and informal curriculum.

In contemporary times, international offerings at institutions have expanded to encompass short courses, summer programs, and degree-granting programs at the undergraduate, graduate, and doctoral levels. International degree-seeking students-at the bachelor's and master's (without thesis) levels - continue to be predominantly Jewish. While tuition paid by these students may represent revenue ventures for some institutions, the state, nonprofit organizations, and Jewish diaspora organizations provide students with financial support with an eye toward promoting solidarity, Jewish identity, and Israel-diaspora relations throughout the world.

\section{Due to the intractable Israeli-Palestin- ian conflict, regional student mobility to Israel is nearly nonexistent.}

In the past, Israel attracted an impressive proportion of the American study abroad population to these programs; in the I996 Open Doors report, Israel was the eighth most popular destination for study abroad for American students, with almost the same number of students studying in Israel $(2,62 \mathrm{I})$ as in all South America $(2,683)$. However, as international student mobility rapidly increased, Israel began to lose ground to other destinations and, in 20I7, Israel fell to an unranked position with 2,435 students. This decrease has multiple causes, including the precarious security situation. However, it is clear that Israel has not been able to maintain its competitive positioning in the United States.

In addition to the traditional Jewish population in international programs, Israel has also fostered exchanges and partnerships for student mobility, particularly with countries of strategic economic and political importance. Beginning in 2008 with the opening of a national Tempus office and the subsequent expansion of Erasmus +, there has been an influx of European students to Israeli campuses; in 20I5-20I7, the Erasmus + program brought 2,47I students and staff from the European Union to Israel. Furthermore, since 20I2, there have been significant government initia- 